\title{
Selection against toxin production in endophyte-infected perennial ryegrass
}

\author{
B.A. TAPPER ${ }^{1}$ and G.C.M. LATCH \\ AgResearch, Grasslands Research Centre, Private Bag 11008, Palmerston North \\ ${ }^{1}$ tapperb@agresearch.cri.nz
}

\begin{abstract}
Strains of perennial ryegrass (Lolium perenne L.) endophyte (Neotyphodium lolii) from nature can be selected by analysis of the alkaloid profiles in plants from diverse seed collections. Lolitrem B, ergovaline, and peramine are the alkaloids of primary interest. The selected endophytes can be cultured and transferred into improved cultivars or breeding lines to reduce or eliminate grazing animal toxicoses while significant plant protection qualities can be maintained. Because the endophytes are transmitted only through seed, stable infections with selected endophytes in pastures can be achieved.
\end{abstract}

Keywords: alkaloids, endophyte, ergovaline, lolitrem, Neotyphodium lolii, peramine, perennial ryegrass

\section{Introduction}

The fungal endophyte, Neotyphodium lolii, is present as mycelium within the inter-cellular space of perennial ryegrass plant. The only way the fungus is known to spread in nature is through mycelium which grows into the developing seed in spring. When the seed germinates the fungus mycelium begins to grow systemically through the above ground parts of the grass.

No contagious spread of the fungus from infected to endophyte-free plants has been observed however the percentage of endophyte-infected ryegrasses present in a pasture may increase. This change in the population over years may be due to the greater competitiveness of the endophyte-infected plants over the endophyte-free, especially in New Zealand, under selective pressure of Argentine stem weevil attack. The presence of buried seed infected with viable endophyte, seed introduced in hay fed out on pastures, or seed carried and spread by animals enhances the opportunity for endophyte-infected plants to dominate in pastures.

Ryegrasses can be artificially infected with mycelium from cultures of endophyte under sterile conditions in a laboratory into endophyte-free seedlings (Latch \& Christensen 1985). This finding raised the possibility that if strains of endophyte were found which did not produce the ryegrass staggers toxins then these strains could be artificially infected into ryegrasses, and seed from plants so infected could give rise to generations of ryegrass pastures free from the risk of ryegrass staggers.

\section{Ryegrass endophyte alkaloids}

There are now recognised three significant classes of alkaloids produced in endophyte-infected ryegrass which are directly relevant to mammalian toxicoses and plant protection.

The lolitrems are a sub-group of indole-diterpenoids and most are potent tremorgens in mammals. Lolitrem $\mathrm{B}$ is the most abundant of them and is considered the principal tremorgen causing ryegrass staggers in grazing animals. Other indole-diterpenoids such as paxilline (Rowan 1993), may also be present in endophyteinfected grasses however these are of lesser potency for causing staggers symptoms and may be of little practical significance in the ryegrass staggers syndrome. They have not been a primary focus of attention for selecting endophytes. Lolitrem B and the closely related compounds accumulate mostly in the leaf sheaths of endophyte-infected plants where endophyte is more abundant. Because they are located in the lower parts of the plant, notably in older leaf sheaths, the ryegrass staggers symptoms are often more acute when animals are grazing lower in the sward particularly during summer and autumn. The amounts of lolitrem B produced may range from barely detectable traces in winter to several $\mu \mathrm{g} / \mathrm{g}$ of dry matter of leaf sheath or flowering heads in summer and autumn.

Ergot alkaloids are also produced in endophyteinfected grasses (Rowan \& Shaw 1987). Ergovaline is recognised as the major ergot alkaloid toxin in ryegrass and is produced in amounts of up to a few $\mu \mathrm{g} / \mathrm{g}$ of dry matter, again predominantly in the lower parts of the vegetative plant as well as in the flowering stems and seedheads. Ergovaline has complex effects on grazing animals. However vasoconstriction and warm ambient temperature hyperthermia in mammals are obvious effects. Other effects include low weight gains and impaired reproductive performance. An interaction of the effects of ergovaline and lolitrems in aggravating the ryegrass staggers syndrome is suspected (Fletcher 1999). While other ergot alkaloids may be produced, 
some as intermediates of ergovaline biosynthesis or metabolism, none are currently recognised as significant mammalian toxins from endophyte-infected ryegrass.

Peramine is the single known member of a distinct type of alkaloid produced by many endophytes of temperate pasture grasses. While having no known toxic effects on grazing animals it is a potent insect feeding deterrent, notably of the adult Argentine stem weevil (Rowan et al. 1990). While its production is always associated with endophyte infection it can be found in parts of the plant, for example upper leaf blades, which are free or nearly free of endophyte. In contrast to lolitrems and ergovaline, it is presumed to be translocated within the plant.

The selection of endophytes for perennial ryegrass initially focused upon finding those strains which produced little or no lolitrem B but which produced sufficient peramine to retain a strong feeding deterrence with insects, notably Argentine stem weevil in the New Zealand pasture context. The simple approach was that ryegrass staggers might be eliminated, or at least much reduced, while a significant and sufficient protection in the pasture to insects would remain from the action of peramine. In approaching this issue it was recognised that lolitrem B, and perhaps other lolitrems, have their own anti-insect activities (Dymock et al. 1989; Prestidge \& Gallagher 1988) but the relative significance of that activity could only be tested in practical pasture situations.

Later the importance of ergot alkaloids, notably ergovaline, as a factor in both animal performance and some insect resistance was recognised and the approach extended to include selection for low or zero production of this compound. Again it was recognised that ergovaline has its own anti-insect activity (Ball et al. 1997).

\section{Detection methods for the alkaloids}

While all three groups of alkaloids can be detected by a variety of methods when in relatively high concentration or after partial purification, the methods of choice for practical detection and quantitative measurement have been based on simple solvent extractions followed by high performance liquid chromatography (HPLC). Both the lolitrems and the ergot alkaloids, notably ergovaline and its naturally occurring isomer ergovalinine, are naturally fluorescent hence sensitive assays and detection are possible with only simple extraction and preparation steps.

Peramine, when present in the amounts considered necessary for insect feeding deterrence of approximately $5 \mu \mathrm{g} / \mathrm{g}$ of dry matter upwards, can be measured by its UV absorbance upon HPLC following an ion exchange pre-separation stage.
Over the last decade the techniques for the detection of the alkaloids have been progressively simplified. Now routinely two samples of leaf sheath pseudo-stem of approximately $25-50 \mathrm{mg}$ dry matter are taken from plants grown in green houses and freeze dried.

For the lolitrem B detection test one of the samples is extracted with $1 \mathrm{ml}$ dichloroethane-methanol, 9:1 v/ $\mathrm{v}$. The extract is used for HPLC on a silica column with a solvent of dichloromethane-acetonitrile, c. 7:1 $\mathrm{v} / \mathrm{v}$ whereupon the lolitrems separate with lolitrem B predominant. They are detected by their fluorescence with excitation at $265 \mathrm{~nm}$ and emission at $440 \mathrm{~nm}$. The detection limit is about $0.1 \mu \mathrm{g} / \mathrm{g}$ of dry matter.

If the plant is free of lolitrems, the second sample is extracted in $1 \mathrm{ml}$ of propan-2-ol-water, $1: 1 \mathrm{v} / \mathrm{v}$, containing $1 \% \mathrm{w} / \mathrm{v}$ lactic acid. The samples and extractant in a $2 \mathrm{ml}$ screw-capped plastic vials are mechanically shaken with glass beads to disrupt the plant pieces, allowed to mix for an hour, and then the extract recovered by centrifugation. Portions of this extract are used to separate ergovaline by C-18 reverse-phase HPLC using a gradient solvent of increasing acetonitrile in water buffered with ammonium acetate. Ergovaline, its naturally occurring isomer ergovalinine, and some other ergot alkaloids (including ergotamine which may be added as an internal standard) can be detected by fluorescence with excitation at $310 \mathrm{~nm}$ and emission at $410 \mathrm{~nm}$ to a detection limit of about $0.1 \mu \mathrm{g} / \mathrm{g}$ of dry matter.

The same extract is used to detect peramine by HPLC in an unusual "pseudo-reverse phase" system (Cox \& Stout 1987) where separation occurs on a silica column using a weakly acidic acetate buffer in solvent of water-methanol, c. 4:1 v/v. Detection is by UV adsorption at $285 \mathrm{~nm}$ to a limit of about $2 \mu \mathrm{g} / \mathrm{g}$.

For the purposes of comparing endophytes the combinations of alkaloids have been described as belonging to chemotypes. In the course of the selective screening of endophyte alkaloids from a wide range of temperate forage grass species just about every possible chemotype combination has been noted including variations of loline patterns in endophytes in various fescues. However lolines are not normally found with the endophytes of perennial ryegrass. Some alkaloid patterns are waiting further investigation before publication while other alkaloid occurrences are reported elsewhere in this volume (Lane 1999). Because of the practical approach of testing first for lolitrems, our findings of numbers with particular chemotype patterns will have been biased to those lacking lolitrems.

\section{Search for desirable strains of endophyte}

A search was made first in New Zealand for strains of endophytes which could produce peramine but were 
incapable of producing lolitrem B. Ryegrasses were collected from many parts of New Zealand and those found to be infected with the endophyte were analysed for the presence of lolitrem B in the plant pseudostems. Many hundreds of plants were analysed but all contained this alkaloid. The search was extended to ryegrasses from overseas countries. A collection, gathered by plant breeding colleagues at Grasslands, of perennial ryegrass seed growing in the wild in Europe was particularly useful. Ryegrass seed was also obtained from the United States Department of Agriculture forage grass seed collection in Washington. Plants grown from these collections were examined for endophyte infection and herbage from all infected plants was analysed for the presence of lolitrem B and peramine. A number of the plants were found to contain peramine but no lolitrem B.

Endophytes from these plants were cultured in the laboratory and two strains, originally considered indistinguishable, were inoculated into seedlings of endophyte-free ryegrasses. For technical simplicity the strains chosen were also relatively easy to culture and transfer into seedlings, firstly of standard test cultivars such as Grasslands Nui and later into more improved cultivar populations. Some of this material progressed through seed multiplication and initial testing with good evidence of peramine production and deterrence of Argentine stem weevil (Popay et al. 1995) while also maintaining an absence of lolitrems and ryegrass staggers in grazing sheep. This was the basis of the Grasslands Pacific Endosafe and Grasslands Greenstone Endosafe combinations, the latter still being available in the market place.

Shortly after entering the market the Grasslands Pacific Endosafe combination was recognised as having a risk that at some stages of development the amount of ergovaline present in the herbage could reach higher levels than normally occurs in standard endophyteinfected perennial ryegrass dominant pastures. This was most notable during flowering and head development, under warm ambient conditions, and with grazing of residues or regrowth soon after the harvest of seed crops.

The potential effects in animals could be seen as comparable to "fescue toxicosis" and "fescue foot" and so Grasslands Pacific Endosafe was withdrawn. The lower levels of ergovaline in Grasslands Greenstone Endosafe together with the situations in which cultivar is usually used have not generated any known difficulties.

Observations and experience after selections had focused upon lolitrem B as the primary grazing animal toxin alerted researchers to the potential risks of ergovaline as a significant toxin affecting animal performance in the standard endophyte-infected ryegrass pasture situation (Easton, 1999). Some effects seen as a part of the ryegrass staggers syndrome may have origins in ergovaline toxicity or may be exacerbated by the presence of ergovaline. Subsequently it was decided that the search must be widened to find and explore strains of endophyte which did not produce lolitrem B or ergovaline.

A modest number of strains of $N$. lolii were found which were incapable of producing lolitrem B and ergovaline but which produced peramine in quantities sufficient to deter Argentine stem weevil. Later collections of ryegrasses from Europe have added to this assemblage of endophytes which have the more desirable alkaloid profile. One of these strains, AR1, has been infected into many different cultivars of ryegrass and is undergoing testing for agronomic performance and any potential toxicity to grazing animals as well as being tested against a number of pasture insect pests. Aspects of this second generation development of selected perennial ryegrass endophyte are discussed elsewhere in this volume.

Endophyte is seed transmitted and will remain viable in the seed for many years if the seed is stored at low temperatures and low seed moisture. If endophyteinfected seed is stored at room temperature the endophyte mycelium will die within 1-2 years whereas the seed may remain viable. It is therefore important that seed is stored under conditions that favour endophyte longevity. We have found that strains of endophyte vary in their tolerance to heat and humidity and hence it is important to select a strain that will not lose its viability too quickly during seed storage.

Selection for viability of endophyte in seed, desirable agronomic characteristics, satisfactory plant protection, demonstration of animal performance, and for maintenance of plant cultivar performance and description where a plant variety right description is established, are all required in an overlapping process taking a few years. Simultaneously there is an opportunity to begin seed multiplication for eventual release of combinations to the market. The maintenance of the desirable alkaloid profile can be reassessed by repeated analyses through seasonal cycles during product development.

In parallel to the development of perennial ryegrass selections, endophytes from tall fescue have been characterised which do not produce ergovaline in that or other pasture species. Lolitrems are not an issue in the tall fescue context, however the loline alkaloids, absent in perennial ryegrass, are a factor. Combinations of improved tall fescue cultivars and selections of endophyte lacking production of ergovaline are being developed in the first instance for markets such as the southern USA where "fescue toxicosis" is considered a major issue. More research will be required before these endophytes in tall fescue could be established with advantage and safety in situations where tall fescue is 
normally grown without any endophyte such as in New Zealand.

Endophytes selected for a desirable set of qualities in one species of grass may be inoculated into other related grass species. However the outcome in terms of stability of endophyte infection through the total life cycle of the plants, including viability within the seed and for the amount of alkaloids, may be rather more variable than when endophyte is transferred within the same species. Even then quantitative variation occurs. Until such times as factors for the maintenance of the symbiotic relationship of the endophytes with their hosts are better understood, our preference is to exploit endophyte selections within the same species.

\section{Genetic characterisation of endophytes}

In parallel to the effort directed at the selection of desirable chemotypes, increasing knowledge and technology for the genetic description of endophytes has become available. Endophytes in culture have been described in terms of isozyme patterns (Christensen et al. 1993) and DNA sequence (Schardl et al. 1994).

Recently a technique has been developed using the polymerase chain reaction (PCR) to examine polymorphic DNA microsatellite sequences. Endophyte within a small section of the plant, or even a single seed, can be characterised to the level of a sub-taxon, e.g., to potentially a sub-species, without needing to isolate the endophyte (Moon et al. 1999). While this technology is not yet optimal for screening for presumptive chemotype selection the results to date are placing each chemotype into one or more sub-taxa entirely consistent with other classifications of endophytes.

\section{Influence of host plant on toxin production}

A decision was made at the beginning of the search for suitable endophytes that the fungus must be incapable of producing undesirable alkaloid toxins. An endophyte which produced a low level of toxin in its original host plant was not considered as best choice. This approach was proven correct when the host plant genotype was shown to sometimes play a crucial role in determining the amount of toxin produced.

One particular strain of endophyte, which produced only a small amount of ergovaline in the plant from which it was originally obtained, was cultured from this plant and infected into 19 endophyte-free Nui seedlings. When the level of ergovaline was determined in each of the 19 infected plants it was found to vary from 3 to 27 $\mu \mathrm{g} / \mathrm{g}$. Hence the level of toxin could be low in one plant and high in another. It has been demonstrated in the
USA that the level of ergovaline toxin in tall fescue breeding lines infected with its normal endophyte $N$. coenophialum can be reduced by selecting the plants which have lower levels of this toxin (Agee \& Hill 1994). However, this method has disadvantages in that the toxin is not eliminated and only one cultivar can be produced after several years of plant selection. By choosing a strain of endophyte that is incapable of producing a particular toxin, this strain can be infected into any endophyte-free cultivar without fear that the toxin will be produced.

\section{Maximising the benefit of endophytes}

Endophytes are capable of producing a range of compounds including plant hormones which might influence the structure, seasonal growth and herbage production of grasses (De Battista et al. 1990). Strains of endophytes differ in the compounds and the quantities of these compounds they produce. The most desirable strains to use are those that are not only harmless to grazing animals and protect the grass from invertebrate pests but which also enhance plant growth and persistence.

The influence of the host plant on ergovaline production has already been discussed. We have also found that ryegrass plants within cultivars, which are infected with the same strain of endophyte, differ in their production of herbage. To get maximum production from a ryegrass cultivar infected with a new strain of endophyte it would be desirable if further selection were made amongst the infected grasses so that those with the most desirable characters could be chosen. At present the AR1 strain of $N$. lolii has been infected into a number of existing ryegrass cultivars and a few prerelease cultivars. To get maximum benefit from this new strain and increase plant yield it will be beneficial in future for plant breeders to select plants that have superior performance. These plants will then form the basis of new higher yielding cultivars.

\section{ACKNOWLEDGEMENTS}

This research has been supported by contracts with the Foundation for Research, Science and Technology. The authors also wish to acknowledge the team within AgResearch Grasslands who have contributed in many ways to the selection and development of endophytes.

\section{REFERENCES}

Agee, C.S.; Hill, N.S. 1994. Ergovaline variability in Acremonium-infected tall fescue due to environment and plant genotype. Crop Science 34: 221-226. 
Ball, O.J.-P.; Miles, C.O.; Prestidge, R.A. 1997. Ergopeptine alkaloids and Neotyphodium loliimediated resistance in perennial ryegrass against adult Heteronychus arator (Coleoptera: Scarabaeidae). Journal of Economic Entomology 90: 1382-1391.

Christensen, M.J.; Leuchtmann, A.; Rowan, D.D.; Tapper, B.A. 1993. Taxonomy of Acremonium endophytes of tall fescue (Festuca arundinacea), meadow fescue ( $F$. pratensis) and perennial ryegrass (Lolium perenne). Mycological Research 97: 10831092.

Cox, G.B.; Stout, R.W. 1987. Study of the retention mechanisms for basic compounds under "pseudoreversed phase" conditions. J. Chromatography 384 : 315-336.

De Battista, J.P.; Bacon, C.W.; Severson, R.F.; Plattner, R.D.; Bouton, J.H. 1990. Indole acetic acid production by fungal endophyte of tall fescue. Agronomy Journal 82: 878-880.

Dymock, J.J.; Prestidge, R.A.; Rowan, D.D. 1989. The effects of lolitrem B on argentine stem weevil larvae. pp. 73-75. In: Proceedings of the $42^{\text {nd }}$ New Zealand Weed and Pest Control Conference.

Easton, H.S. 1999. Endophyte in New Zealand ryegrass pastures: an overview. Ryegrass endophyte: an essential New Zealand symbiosis. Grassland Research and Practice Series No. 7: 1-9.

Fletcher, L.R. 1999. "Non-toxic" endophytes in ryegrass and their effect on livestock health and production. Ryegrass endophyte: an essential New Zealand symbiosis. Grassland Research and Practice Series No. 7: 133-139.

Lane, G.A. 1999. Chemistry of endophytes: patterns and diversity. Ryegrass endophyte: an essential New Zealand symbiosis. Grassland Research and Practice Series No. 7: 85-94.
Latch, G.C.M.; Christensen, M.J. 1985. Artificial infection of grasses with endophytes. Annals of Applied Biology 107: 17-24.

Moon, C.D.; Tapper, B.A.; Scott, B. 1999. Identification of Epichloë endophytes in planta by a microsatellitebased PCR fingerprinting assay with automated analysis. Applied and Environmental Microbiology 65: 1268-1279.

Popay, A.J.; Hume, D.E.; Mainland, R.A.; Saunders, C.J. 1995. Field resistance to Argentine stem weevil (Listronotus bonariensis) in different ryegrass cultivars infected with an endophyte deficient in lolitrem B. New Zealand Journal of Agricultural Research 38: 519-528.

Prestidge, R.A.; Gallagher, R.T. 1988. Endophyte fungus confers resistance to ryegrass: Argentine stem weevil larval studies. Ecological Entomology 13: 429-435.

Rowan, D.D. 1993. Lolitrems, peramine and paxilline: mycotoxins of the ryegrass/endophyte interaction. Agriculture, Ecosystems and Environment 44: 103122.

Rowan, D.D.; Dymock, J.J.; Brimble, M.A. 1990. Effect of fungal metabolite peramine and analogs on feeding development of Argentine stem weevil (Listronotus bonariensis). Journal of Chemical Ecology 16: 1683-1695.

Rowan, D.D.; Shaw, G.J. 1987. Detection of ergopeptine alkaloids in endophyte-infected perennial ryegrass by tandem mass spectrometry. New Zealand Veterinary Journal 35: 197-198.

Schardl, C.L.; Leuchtmann, A.; Tsai, H.F.; Collett, M.A.; Watt, D.M.; Scott, D.B. 1994. Origin of a fungal symbiont of perennial ryegrass by interspecific hybridization of a mutualist with the ryegrass choke pathogen, Epichlö typhina. Genetics 136: 13071317. 
